\title{
RECURRENT OTOGENIC TEMPORAL LOBE ABSCESS: A CASE REPORT
}

\author{
S. Satyananda Rao1, Ravi Kishore $\mathrm{H}^{2}$, Abhilash A. M33, Paparaja $\mathrm{S}^{4}$
}

\section{HOW TO CITE THIS ARTICLE:}

S. Satyananda Rao, Ravi Kishore H, Abhilash A.M, Paparaja S. "Recurrent Otogenic Temporal Lobe Abscess: A Case Report". Journal of Evolution of Medical and Dental Sciences 2014; Vol. 3, Issue 06, February 10; Page: 1315-1319, DOI: $10.14260 /$ jemds/2014/1985

ABSTRACT: Complication of otitis media is defined as a spread of infection beyond the pneumatised area of temporal bone and associated mucosa. Though introduction of antibiotics has decreased the incidence of intracranial complications, they still occur in unrecognized, poorly managed or resistant cases which lead to morbidity and mortality. Here we report a case of chronic otitis media with recurrent temporal lobe abscess leading to mortality.

INTRODUCTION: Complications of acute and chronic otitis media have become a rare event these days. Nevertheless, unrecognized, poorly managed or resistant infections can potentially lead to such complications. ${ }^{1}$

Brain abscess as second most common intracranial complication of otitis media after meningitis accounting for mortality rate ranging 7-60\%.2,3 The commonest organism causing brain abscess following an otogenic source include Staphylococcus aureus, Streptococcus pneumonia, Haemophilus influenza, Escherichia coli, proteus \& Pseudomonas species.

We report a case of recurrent temporal lobe abscess secondary to chronic otitis media leading to mortality.

CASE HISTORY: A thirteen year old boy was first admitted with an eight days history of fever, drowsiness, lethargy and poor oral intake. He also had on and off discharge from left ear for the past three months.

Clinically he was conscious, alert, and confused, had temperature $39.4^{\circ}$ and tachycardia (108 beats/min). No signs of meningeal irritation observed. His pupils and fundus examination were normal. His left ear examination showed characteristic foul smelling, non-blood stained purulent discharge and attic cholesteatoma. His cardiovascular, respiratory and abdominal examinations were within normal limits.

With the above picture left chronic otitis media with cholesteatoma with intracranial complication was suspected clinically.

His investigations revealed Hemoglobin $12 \mathrm{gm} / \mathrm{dl}$, white blood cell count $17000 / \mathrm{mm}^{3}$ with neutrophil count $80 \%$. Biochemical parameters were within normal limits. CT brain with contrast showed two thin walled ring enhancing lesions in left temporal lobe(size of the largest lesion is $42 \mathrm{~mm} \times 33 \mathrm{~mm} \times 25 \mathrm{~mm}$ ) with mild mass effect suggesting an abscess(Fig. I). Patient was referred to neurosurgeon for further management. At neurosurgery craniotomy done and abscess was drained. The follow up CT brain taken on seventh postoperative day showed reduced left temporal lobe abscess (Fig. II). Patient was discharged on tenth postoperative day after recovering from neurological symptoms. Patient was advised to undergo ear surgery. However patient did not turn up for follow up. 
After 1 year, he presented in the department of otolaryngology with a history of foul smelling discharge and pain in the left ear. He also had headache, fever for the past 7days, vomiting since 1 day. He was conscious, oriented but drowsy, had no signs of meningeal irritation and his fundoscopic examination is normal. Otologic examination shows foul smelling purulent ear discharge and attic cholesteatoma of left ear. His cardiovascular, respiratory, abdominal examination was within normal limits.

His investigations showed white blood cell count 13000 cells $/ \mathrm{mm}^{3}$ with $70 \%$ neutrophils. Biochemical parameters were within normal limits. Contrast enhanced MRI brain showed recurrence of left temporal abscess at the same site (Fig. III).

After stabilizing the patient craniotomy was done and abscess was drained. Abscess material was processed in lab revealed Proteus vulgaris. Patient was discharged well and asymptomatic on twentieth post-operative day and adviced again for further otological management. Patient died 10 days after discharge.

DISCUSSION: Though chronic otitis media with intracranial complications is on the decline, ${ }^{4}$ they continue to be an important health issue in developing countries. The incidence of intracranial complications caused by otitis media was reported to have been decreased from $2.3 \%$ in the preantibiotic era to around $0.1 \%$. However, even in this $21^{\text {st }}$ century otogenic brain abscess is still reported as life threatening complication. ${ }^{6-8}$ Osama et al reported that most frequent intracranial complication of otitis media is meningitis (1.4\%) followed by brain abscess $(0.35 \%) .{ }^{9}$

Otogenic brain abscesses are often the result of venous thrombophlebitis rather than direct dural extension. Osteitis or granulation tissue causes retrograde thrombophlebitis of dural vessels that terminate in the white matter of the brain, ${ }^{10}$ producing encephalitis. This localized encephalitis progresses to necrosis and liquefaction of brain tissue with surrounding edema.

CT and MRI are the important tools that enable in making an accurate diagnosis of the infection. In this patient, the diagnosis of the brain abscess was established by a CT scan for first time and MRI on second presentation.

Multiple organisms are usually present in brain abscesses. ${ }^{10}$ Polymicrobial cultures with a high incidence of anaerobes are reported in various studies. ${ }^{10}$ Streptococcus and Staphylococcus are common gram positive organisms that are isolated from brain abscesses. Escherichia and Proteus, Klebsiella and Pseudomonas species are typical gram-negative isolates. In this patient we isolated proteus vulgaris.

Brain abscess formation is indicated by the presence of the triad of headache, high-grade fever, and focal neurologic deficits. In more recent times, the complete triad is not frequently encountered. Symptoms may be present for 2 weeks before the brain abscess is fully formed. ${ }^{10}$ Focal deficits depend on the location of the abscess. Cerebellar abscesses provoke dizziness, ataxia, nystagmus and vomiting. Temporal lobe lesions may result in seizures. Associated signs of meningitis are usually present. ${ }^{10}$ Papilledema is frequently seen in stage 3 of abscess formation. ${ }^{10}$

The standard approach for Otogenic brain abscess is craniotomy and excision of abscess followed by a mastoidectomy performed as second procedure. Fleisher reported that the surgical procedure is decided based on the patient's general condition, the location of the brain abscess and efficacy of antibiotics. ${ }^{11}$ When conservative therapy is insufficient, there is general agreement that surgical treatment of brain abscess is necessary. 
In our case the patient was treated empirically with systemic antibiotics, steroids and antiepileptics on admission. After improving the general condition, the patient was taken for craniotomy and drainage of abscess. Patient was discharged symptom free during both instances. However, patient did not return for follow up even after specific instructions to attend left chronic otitis media with cholesteatoma which had resulted in brain abscess.

CONCLUSION: Poor follow up is also a predictor of mortality in otogenic brain abscess along with virulence of organism, poor resistance of the patient and resistance of organism to antibiotics. Thus post-operative follow up and management of ear pathology is very necessary.

\section{BIBLIOGRAPHY:}

1. Oliver FA, Craig AB. Cholesteatoma. In: Otology, Neurology and Lateral Skull Base Surgery.1 $1^{\text {st }}$ ed. Indian imprint: Thieme Publishers; 2011.p.136-144.

2. Sennaroglu, Levent and Bulent Sozeri. Otogenic brain abscess: review of 41 cases. Otolaryngology-Head and Neck Surgery 123.6 (2000): 751-755.

3. Garcia BA, Varquez GE, Benito N, et al. Brain Abscess. Clinicomicrobiologic study and prognostic analysis of 59 cases. Rev Clin Esp 1998; 198:413-9.

4. Kurien, Mary et al. Otogenic intracranial abscess: concurrent craniotomy and mastoidectomy-changing trends in a developing country. Archives of Otolaryngology-Head \& Neck Surgery 124.12 (1998): 1353.

5. Delbrouck, C., A. L. Mansbach and P. Blondiau. Otogenic thrombosis of the lateral sinus: report of a case in a child. Acta oto-rhino-laryngologica Belgica 50.3 (1995): 221-226.

6. Kuczkowski, Jerzy and Bogusław Mikaszewski. Intracranial complications of acute and chronic mastoiditis: report of two cases in children. International journal of pediatric otorhinolaryngology 60.3 (2001): 227-237.

7. Greenberg, Jayson S. and Spiros Manolidis. High incidence of complications encountered in chronic otitis media surgery in a US metropolitan public hospital. Otolaryngology--Head and Neck Surgery 125.6 (2001): 623-627.

8. Paolini S., Ralli G., Ciappetta P. \& Raco A. Gas-containing otogenic brain abscess. Surgical neurology 2002, 58(3), 271-273.

9. Osma Ustun, Sebahattin Cureoglu and Salih Hosoglu. The complications of chronic otitis media: report of 93 cases. Journal of laryngology and otology 114.2 (2000): 97-100.

10. Samuel Julian, Carlos Fernandes and Johannes L. Steinberg. Intracranial otogenic complications: a persisting problem. The Laryngoscope 96.3 (1986): 272-278.

11. Watanabe, Ken-ichi et al. Brain abscess secondary to the middle ear cholesteatoma: a report of two cases. Auris Nasus Larynx 31.4 (2004): 433-437. 


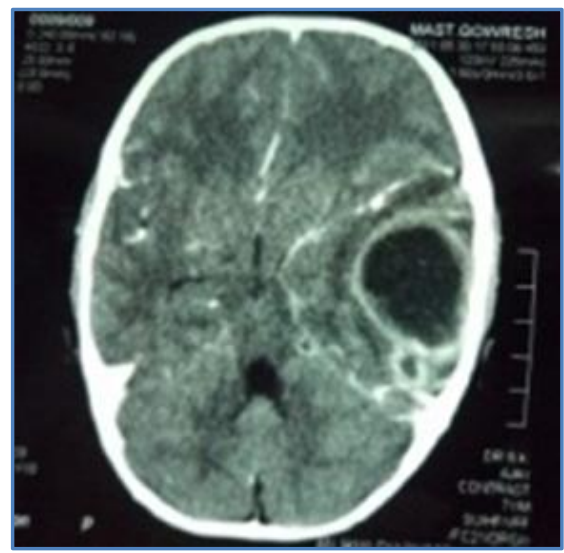

Fig. 1: CECT brain showing Two thin walled ring enhancing lesions in left temporal lobe (temporal lobe abscess)

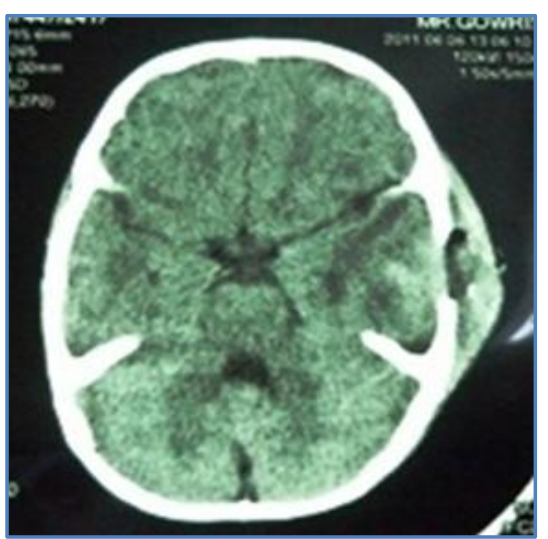

FIG. 2: Post-operative Follow-up CECT brain Showing resolution of the brain abscess

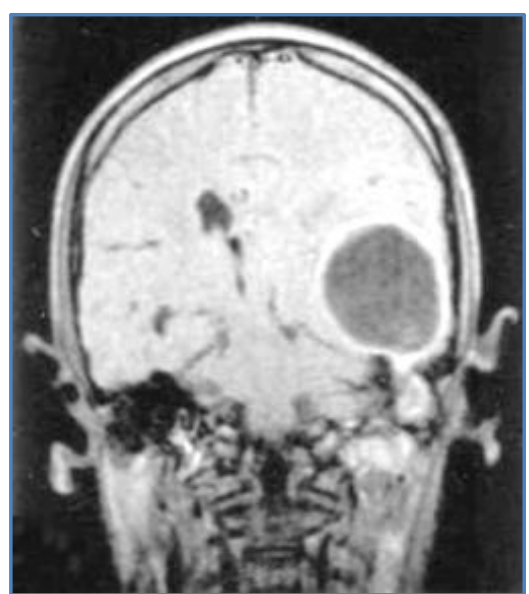

Fig. 3: Contrast enhanced MRI brain showing recurrence of left temporal abscess 


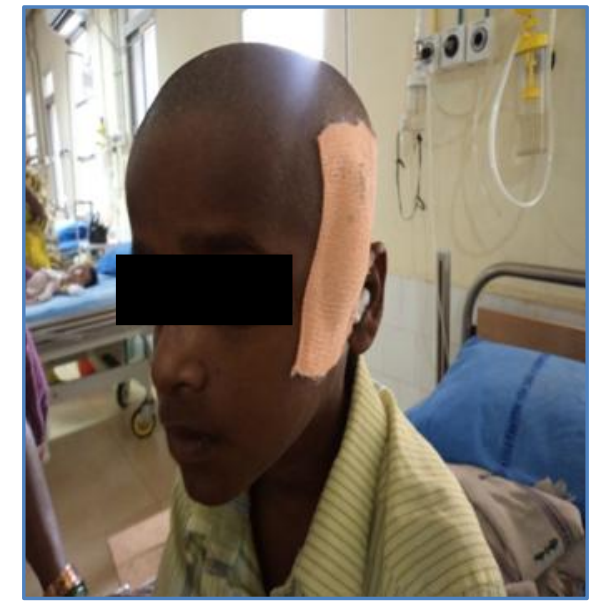

\section{Post Operative image of the patient}

\section{AUTHORS:}

1. S. Satyananda Rao

2. Ravi Kishore $\mathrm{H}$.

3. Abhilash A. M.

4. Paparaja S.

\section{PARTICULARS OF CONTRIBUTORS:}

1. Professor and Head, Department of Otorhinolaryngology, Vijaynagar Institute of Medical Sciences, Bellary, Karnataka, India.

2. Associate Professor, Department of Otorhinolaryngology, Vijaynagar Institute of Medical Sciences, Bellary, Karnataka, India.

3. Assistant Professor, Department of Otorhinolaryngology, Vijaynagar Institute of Medical Sciences, Bellary, Karnataka, India.
4. Post Graduate Trainee, Department of Otorhinolaryngology, Vijaynagar Institute of Medical Sciences, Bellary, Karnataka, India.

\section{NAME ADDRESS EMAIL ID OF THE CORRESPONDING AUTHOR:}

Dr. Ravi Kishore H, Associate Professor, Department of ENT, VIMS, Bellary - 583108.

E-mail: ravikishore_ent@yahoo.com

Date of Submission: 03/01/2014. Date of Peer Review: 04/01/2014. Date of Acceptance: 24/01/2014. Date of Publishing: 04/02/2014. 